\title{
The Role of Minimal Intervention in Orthodontics
}

\author{
J on Årtun
}

Department of Developmental and Preventive Sciences, Faculty of Dentistry, Kuwait University, Kuwait

\begin{abstract}
Less than $15 \%$ of the population develops a normal occlusion as defined by Angle in the permanent dentition. The term 'ideal' may therefore be a more appropriate description, and deviations from this esthetic and functional optimum should not be considered abnormalities in the true sense of the word. Current research indicates that few malocclusions compromise dental, periodontal or temporomandibular health. To determine whether or not protruded, irregular or maloccluded teeth merit orthodontic intervention is therefore a major challenge. Another challenge is to determine to what extent a limited treatment strategy may be successful in correcting the occlusal problems according to the perceived needs of the patients. I discuss these issues in my present communication and conclude that the major reasons for recommending orthodontic treatment are psychosocial in nature. I also conclude that the majority of the orthodontic cases require comprehensive treatment to achieve successful results. Orthodontic patients are typically satisfied with the outcome of the orthodontic intervention, reporting that the esthetic improvements and the increased functional comfort of the dentition have made significant contributions to their quality of life. Technological advances have made orthodontic treatment simpler and safer over the years. Considering the potential for long-lasting results and the low risk of
\end{abstract}

iatrogenic effects if the patients comply with appropriate oral hygiene measures during active appliance therapy, I conclude that treatment of minor occlusal deviations may also be justified in subjects expressing a clearly defined subjective need for treatment.

Copyright $@ 2002$ S. Karger AG, Basel

\section{Normal Occlusion versus Malocclusion}

Edward H. Angle [1] played a major role in developing a concept of occlusion in the natural dentition. His postulate was that the mesiobuccal cusps of the maxillary molars should occlude in the buccal groove of the mandibular molars. Given that molar relationship, and that the teeth in each arch are arranged on a smoothly curving line - defined by Angle as the 'line of occlusion' - the occlusion would be normal. That brilliant simplification made more than 100 years ago has been proven to be correct, provided that there are no aberrations in the size and shape of the teeth. Any deviation from this ideal occlusal scheme was defined as a malocclusion, of which Angle described three different classes [1]. Class I malocclusion was characterized by a normal molar relationship but abnormal line of occlusion due to tooth malpositions, tooth rotations or other deviations. Class II malocclusion was characterized by an abnormal molar relationship due

\begin{tabular}{ll}
\hline KARGER & (c) 2002 S. Karger AG, Basel \\
1011-7571/02/0115-0007\$18.50/0 \\
$\begin{array}{l}\text { Fax +4161306 1234 } \\
\begin{array}{l}\text { E-Mail karger@karger.ch } \\
\text { www.karger.com }\end{array}\end{array}$ & $\begin{array}{l}\text { Accessible online at: } \\
\text { www.karger.com/journals/mpp }\end{array}$
\end{tabular}

Prof. Jon Årtun, DDS, Dr. odont.
Department of Developmental and Preventive Sciences
Faculty of Dentistry, Kuwait University
PO Box 24923
Safat 13110 (Kuwait) 
to distal position of the mandibular molars relative to the maxillary ones. Finally, class III malocclusion was characterized by an abnormal molar relationship due to mesial position of the mandibular molars relative to the maxillary ones.

\section{Need for Orthodontic Treatment and Type of Intervention}

Data from large-scale surveys made in the USA during the 1970 s suggest that less than $15 \%$ of the population are destined to develop a normal occlusion according to Angle in the early permanent dentition $[2,3]$. The term 'normal' in this context should therefore by no means be confused with what commonly occurs. 'Ideal occlusion' may be a more appropriate term. Similarly, not every occlusal deviation from the esthetic and functional optimum described by Angle should be considered an abnormality in the true sense of the word. Determining how severely teeth are protruded, irregular or maloccluded and whether or not they merit orthodontic intervention is therefore a major challenge. Possible reasons for therapy may be categorized as preventive, functional or psychosocial [4]. In addition, orthodontic treatment may in some situations be recommended as an adjunct to various dental interventions in order to achieve optimal results. Another challenge is to determine to what extent a limited treatment strategy may be successful in correcting the occlusal problems according to the perceived needs of the patients. The following is a discussion of these issues, focusing on the role of minimal intervention in orthodontics.

\section{Treatment for Preventive Reasons}

Certain occlusal deviations may be associated with an increased risk of traumatic injuries to the teeth or represent a challenge to dental and periodontal health. If so, patients presenting with such types of malocclusion may benefit from orthodontic treatment for preventive reasons.

Traumatic Injuries. It is well established that the protrusion of maxillary incisors is a strong risk factor for traumatic dental injuries [5-7]. One study concluded that about one third of children with untreated class II malocclusion are likely victims of fractures or devitalization of one or more maxillary incisors due to significant dental traumas [5]. The mechanism may be that the increased overjet frequently accompanying a class II molar relationship may prohibit closure of the lips in a relaxed position, thereby depriving the incisors of their otherwise natural protection $[6,7]$. For that reason, patients presenting with incompetent lips concomitant with a large overjet may benefit from normalization of the condition (fig. 1), preferably as early as possible. A relatively minor intervention using different types of removable, functional appliances or extraoral tractions, either alone or in combinations, may produce a reduction of the distal occlusion and overjet in the early mixed dentition $[8,9]$. However, the treatment time associated with an appropriate amount of correction is considerable, including frequent follow-up visits and appliance adjustments [8, 9]. In addition, most cases require a second treatment phase with full fixed appliances following the eruption of premolars and canines to achieve successful occlusal results [8-10].

When presenting for treatment, the patient in figure 1 was more concerned with the negative impact of the incisor position on his appearance than with the potential risk of injury it represented. He was therefore very pleased with the posttreatment result and reported that he no longer was a target for teasing. For lack of comparison he had not been aware of any functional problems associated with his malocclusion but could definitely tell the difference after appliance removal. The increased comfort during chewing and articulation of sounds added to his feeling of satisfaction. Such benefits would have been impossible without a comprehensive treatment with full fixed appliances.

Caries and Periodontitis. Studies in young individuals have concluded that well-aligned teeth may be more conducive to good oral hygiene and gingival health than crowded dentitions [11-13]. Furthermore, it has been suggested that malalignment decreases the effect of average oral hygiene measures [12,14], while the influence of tooth irregularity on gingival and periodontal health may be masked in subjects with poor or good oral hygiene [14]. It may be speculated, therefore, that orthodontic unraveling of malaligned teeth may reduce the potential for caries and periodontitis in adolescents who fall within the 'average' oral hygiene group. Another argument for orthodontic treatment may be to reduce the potential for occlusal traumatism, which may be considered a risk factor for periodontal destruction [15].

A follow-up evaluation of a large group of adults aged 35 years and above failed to detect any effect of crowding or spacing on caries [16]. Similarly, large groups of adults who had received orthodontic treatment about 20 years earlier did not have a better periodontal status than untreated controls, despite superior occlusion of the treated subjects $[17,18]$. Finally, experimental studies 

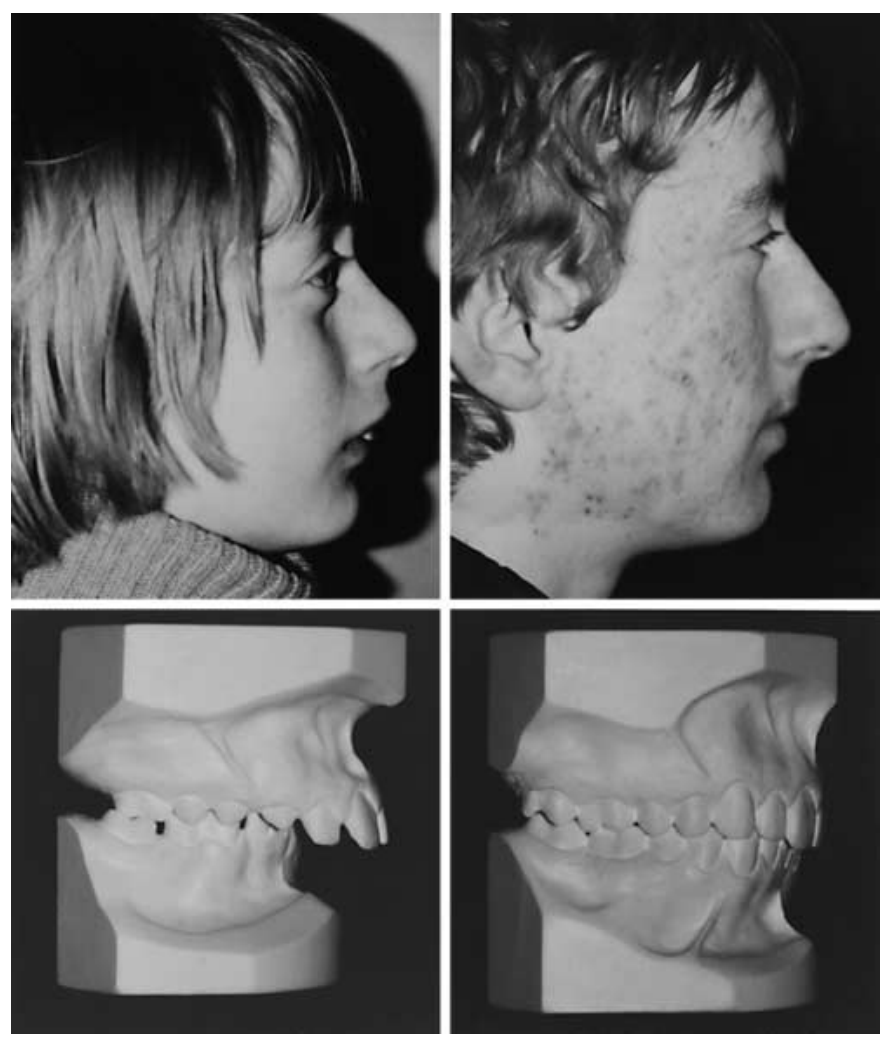

Fig. 1. Pre- and posttreatment records of adolescent patient presenting with severe class II, division 1 malocclusion and incomplete lip closure. Note ideal occlusion and harmonious profile after treatment.

have failed to detect increases in plaque-associated periodontal attachment loss in the presence of occlusal traumatism [19]. Malocclusion may therefore not be a risk factor for caries, and its effect on periodontal disease may be limited to severe overbite cases demonstrating direct impingement of the incisal edges on the soft tissue in the opposing arch [20]. Successful correction of such occlusal deviations requires comprehensive orthodontic treatment $[21,22]$.

The major reason for orthodontic unraveling of severely crowded incisors (fig. 2) may be to improve esthetics [23-25] and therefore the emotional well-being of the patient. The potential for spontaneous reduction in incisor malalignment following serial extraction treatment is well documented. However, the indication for that type of minimal intervention is limited to the subgroup of patients with arch length deficiency that present with a class I molar relationship and are diagnosed to need premolar extraction. A comprehensive approach is mandatory if a class II tendency is present, as well as whenever a
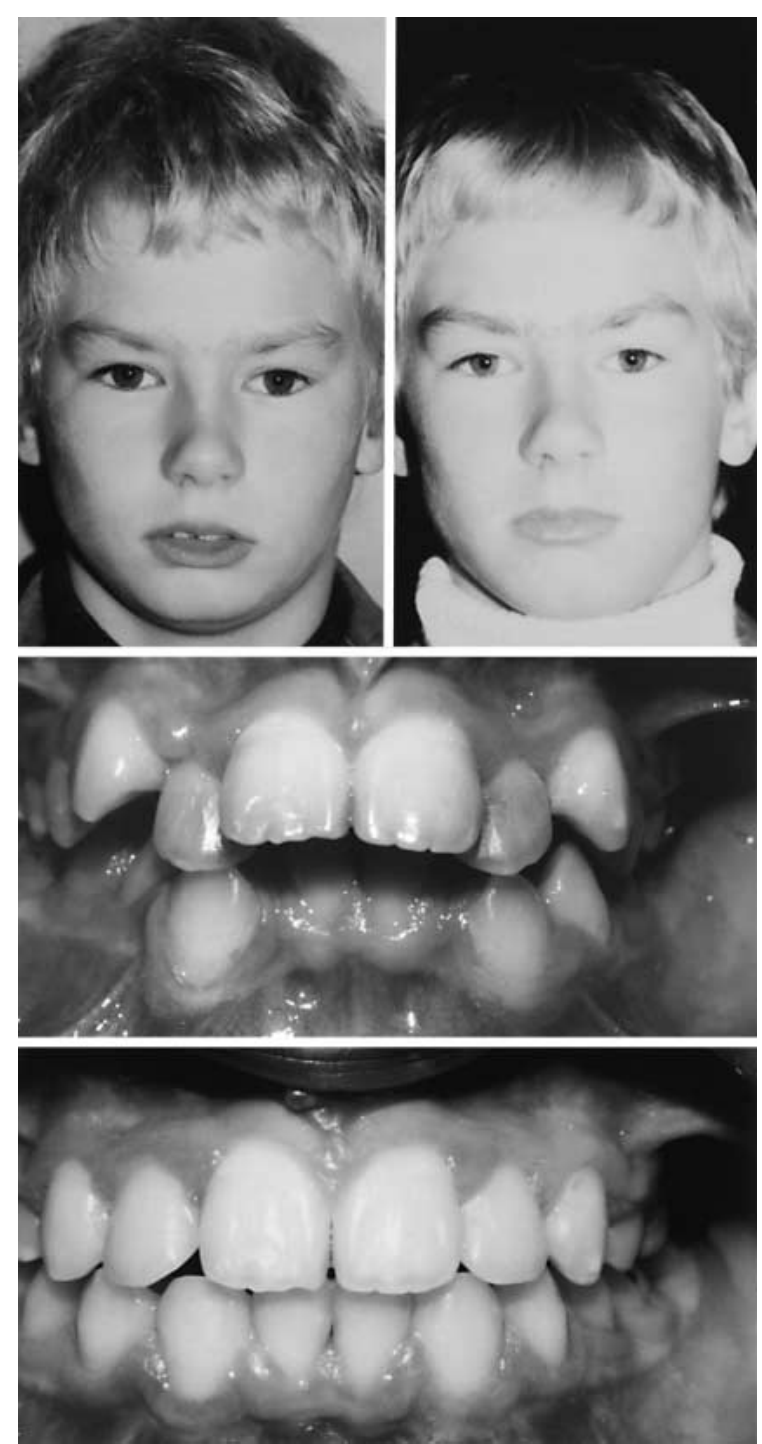

Fig. 2. Pre- and posttreatment records of adolescent patient presenting with severe malalignment of the anterior teeth in both arches and incomplete lip closure. Note well-aligned teeth and favorable lip position after treatment.

nonextraction strategy is preferable. Moreover, the majority of serial extraction cases need a period of full fixed appliance therapy after eruption of the canines and second premolars to achieve optimal esthetic results [26, 27]. Finally, recent research suggests that rotated maxillary incisors should be slightly overcorrected during active treatment to provide leeway for relapse without re-expression of irregularity [28]. Such overcorrection can only be achieved by comprehensive treatment with fixed appliances. 


\section{Functional Reasons}

For obvious reasons, a severe malocclusion may compromise all aspects of oral and temporomandibular (TM) function. Patients with severe discrepancies in incisor occlusion may have difficulties incising food or articulating certain sounds, and mastication may be compromised if several antagonistic teeth lack appropriate surface contact. Certain malocclusions may also be associated with a mode of function that in turn may have a negative impact on TM health through predisposing the patient to TM disorders.

Mastication. Most orthodontists have experienced that their patients report on a more comfortable and enjoyable eating process and an improved capacity for chewing after successful occlusal corrections. However, due to a lack of good tests for chewing ability and of objective measures for any functional handicap, scientific information in this area is very limited. Although patients presenting for combined orthodontic and surgical correction report on improved chewing ability after correction of the severe malocclusions [29], the associations between malocclusion and chewing are weak in adolescent orthodontic patients [25]. Mastication is therefore unlikely to be a major problem for patients who are able to make incisor contact during functional jaw movements and who demonstrate bilateral contact of the posterior segments in centric occlusion.

Speech. Clinical examinations suggest that subjects with open bite as well as anterior and posterior crossbite are at increased risk of producing consonants too far anteriorly [30]. In addition, questionnaire examinations have revealed an association between self-reported speech problems and professional occlusal indexes [25]. However, the associations have not been found to be strong $[25,30]$. Also, a recent clinical finding suggests that articulation problems on the first day with retainers decrease to insignificant levels after a week [31]. The tongue may therefore have the ability to adapt to different occlusal anomalies in the anterior segment, supporting the findings of weak associations between malocclusions and speech.

TM Disorders. According to the American Dental Association, the term TM disorders refers to a cluster of disorders [32], characterized by pain in or around the TM joint or muscles of mastication, by mandibular dysfunction such as limitations or deviations in opening and by joint sounds during functional jaw movements. There is general agreement that the etiology of TM disorders is multifactorial [33] and that emotional disturbances and stress are major etiological factors [34-36]. However, while malocclusion may be associated with morphological changes in the TM joint with age [37], any contributory effect of discrepancies in occlusal morphology and function on TM disorders is unclear. Few studies have found positive associations [38-40], and common trends are rare. It is unlikely that the morphological discrepancy per se is a risk factor. Rather, certain types of malocclusion may be associated with a mode of function that in turn may predispose the subject to TM disorders. Accordingly, some studies conclude that occlusal supracontacts [39], nonworking side interferences [38-40] and abnormal slides from centric relation to centric occlusion [38-40] occur more frequently in subjects with pain and dysfunction of the TM joint than in the normal population. However, the associations are not strong [38-40], and several well-controlled studies have failed to identify any morphological or functional occlusal parameters as risk factors [41-43].

Minimal interventions such as occlusal equilibration [44] or splint therapy [45] may be successful if the objectives are limited to the elimination of occlusal interferences and alleviation of orofacial pain. However, a comprehensive treatment approach with fixed appliances is mandatory if the objectives include a good occlusion with well-aligned arches. The patient in figure 3 had consulted several health professionals regarding her TM condition and was finally referred for orthodontic treatment for functional reasons. She presented with reduced jaw opening, pain in the masseter and temporalis muscles on palpation and audible clicking in the right TM joint. She reported difficulties in finding a 'stable' occlusion, and resistance to manipulation prohibited guidance of the mandible into the different diagnostic positions. She had a crossbite and reduced occlusal contacts on the right side. In attempts to avoid orthodontic treatment for the wrong reasons, she was made aware of the lack of scientific evidence that her TM ailment was related to her malocclusion. Despite that, she still expressed a desire for treatment. Her motivation was to correct the uneven line of occlusion that was evident on smiling (fig. 3). Fixed appliances were mounted after an initial phase of splint therapy. The treatment was uneventful, and the patient was very satisfied with the esthetic and functional results (fig. 3). Her TM health improved during the course of treatment, and her symptoms of disorder were more or less gone at the time of appliance removal. The most likely explanation for this favorable response is the combined effect of the splint therapy and the fact that she was happier and felt better after the orthodontic treatment. 

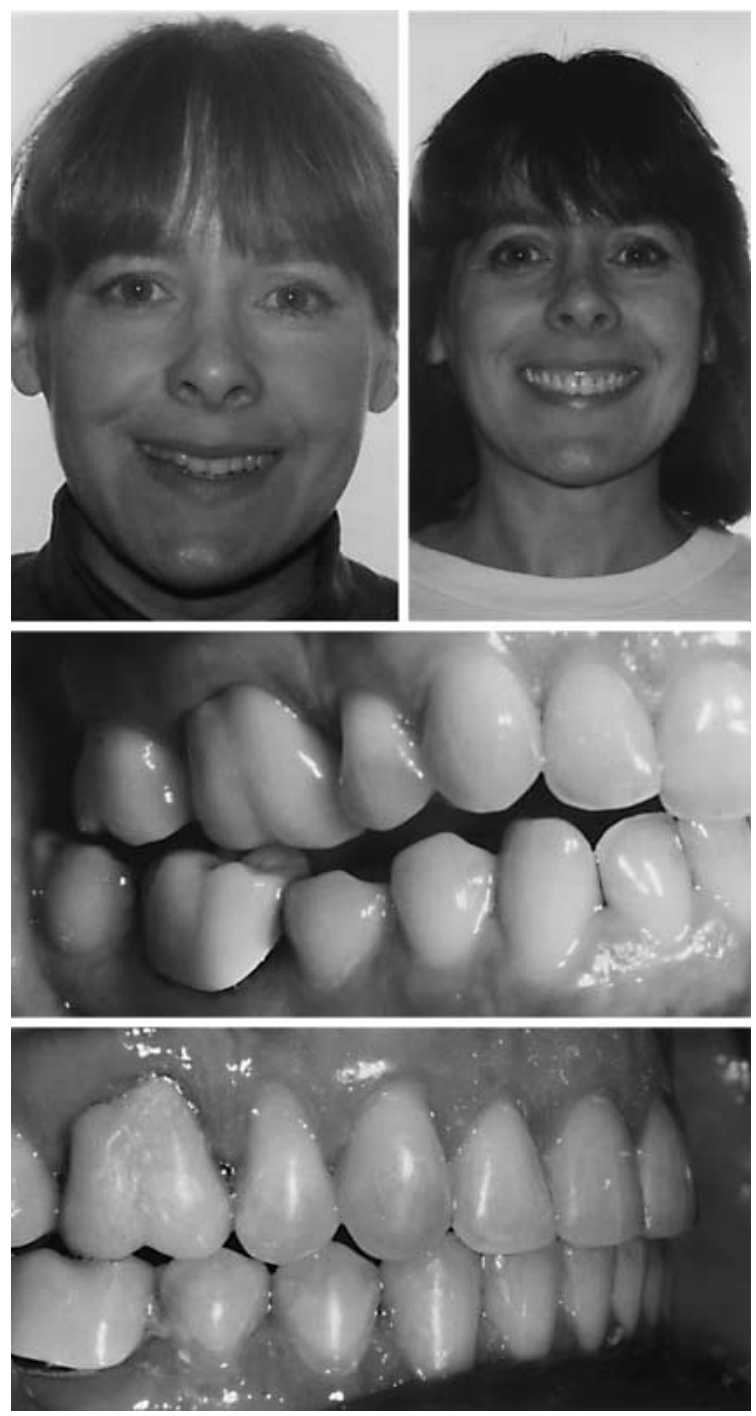

Fig. 3. Pre- and posttreatment records of adult patient presenting with crossbite and open bite in the posterior segment. She also presented with an uneven occlusal plane, which was evident on smiling. Note ideal occlusion and even occlusal plane after treatment.

Functional Shifts. A unilateral posterior crossbite is typically associated with a lateral functional shift in the mixed dentition [46] as opposed to the adult dentition [47]. These findings may indicate a potential for adaptive remodeling changes of the TM joint with age, resulting in a skeletal asymmetry [48]. To minimize that risk, and to restore facial symmetry in centric occlusion by elimination of the shift, such patients may benefit from treatment in the early mixed dentition (fig. 4). Treatment with a maxillary expansion device is typically successful in less than 6 months [48]. For similar reasons, patients that shift into a negative overjet from centric relation to centric
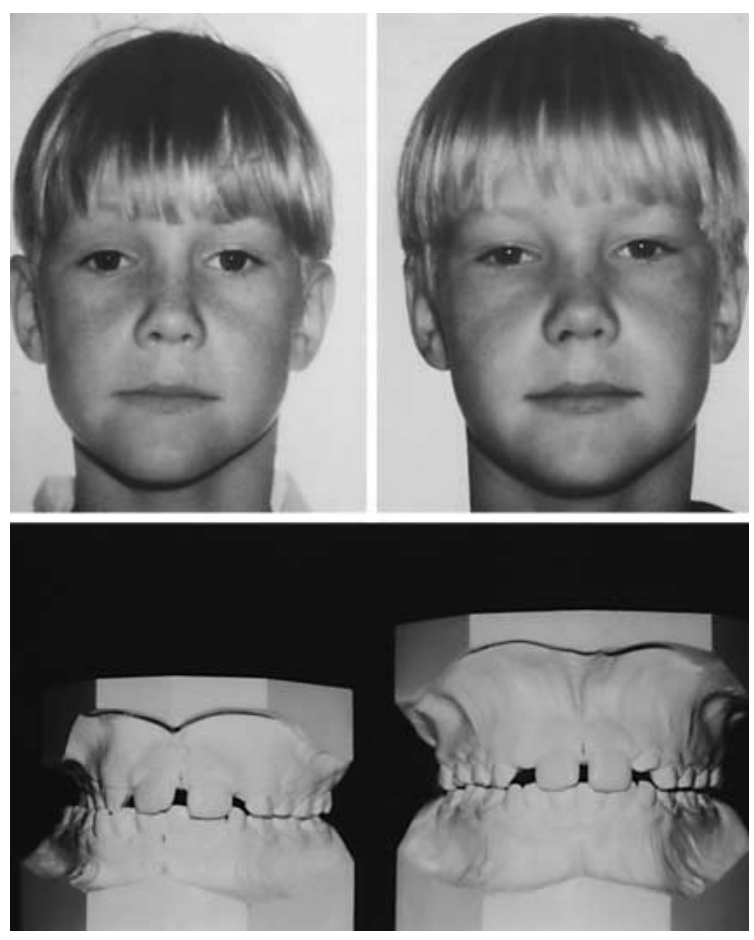

Fig. 4. Pre- and posttreatment records of adolescent patient presenting with functional unilateral posterior crossbite. Note improved facial symmetry and nearly coinciding dental midlines following correction of the crossbite and elimination of the shift.

occlusion should be treated as early as possible [49, 50]. A positive overjet may also be established in patients without a detectable shift after a period ranging from 6 to 8 months with protraction headgear attached to a fixed maxillary splint. The first phase for correction of posterior or anterior crossbite may be considered limited treatment. However, about one third of the class III patients without a shift demonstrate relapse in the early permanent dentition [51], requiring a comprehensive treatment approach. A comprehensive approach may also be called for to correct any tooth malalignment developing in the early permanent dentition, despite stability of the early correction of the crossbite or the negative overjet.

\section{Psychosocial Reasons}

As discussed in the previous paragraphs, only a small proportion of the population has malocclusions with a defined preventive or functional need for orthodontic treatment. The major justifications for orthodontic therapy are therefore psychosocial in nature. Most patients, particularly adults [23], report that dissatisfaction with their dental appearance is the major motivation for seek- 

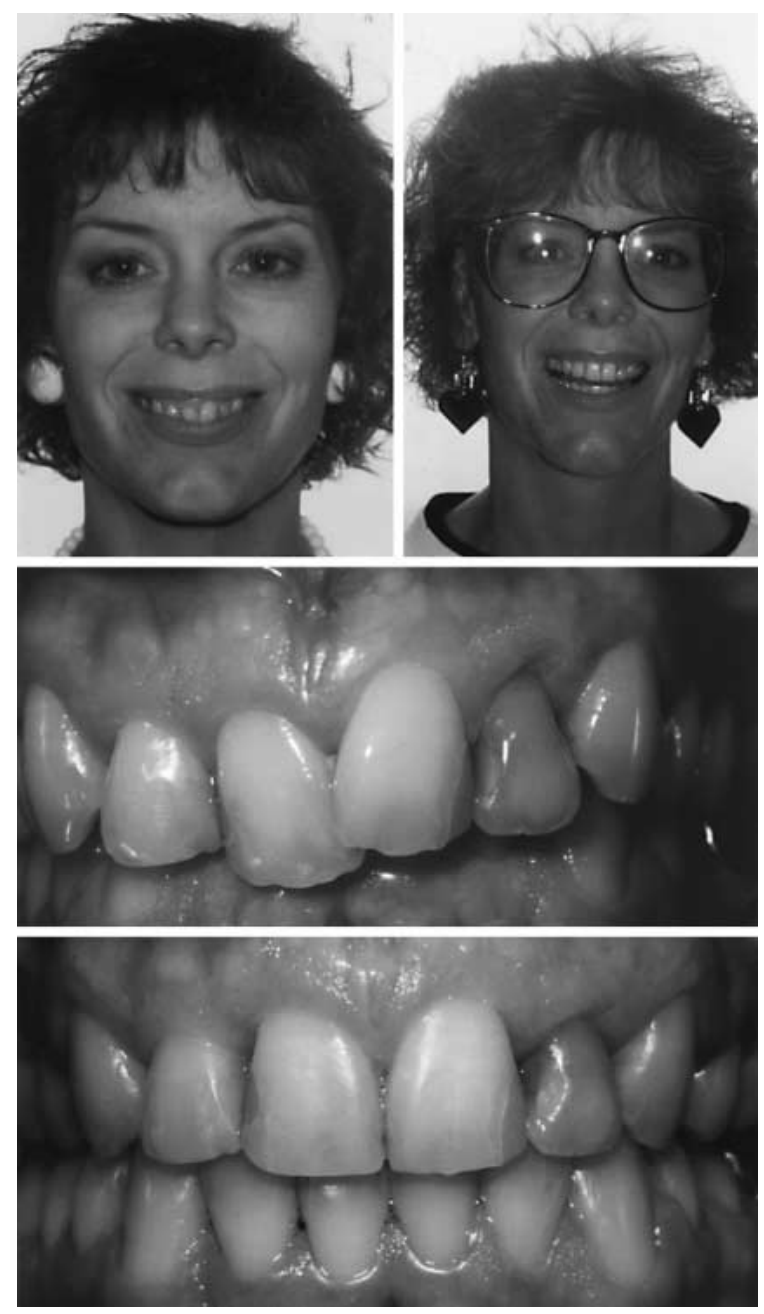

Fig. 5. Pre- and posttreatment records of adult patient presenting with deep bite and malaligned maxillary incisors. Note well-aligned teeth and improved appearance on smiling after treatment.

ing orthodontic treatment. In retrospect, the vast majority of the patients are satisfied with the active treatment results $[23,24]$. Knowing the implications and the outcome, they would not hesitate to go through treatment once again [23]. A typical example is the patient in figure 5. She had several large restorations and a couple of endodentically treated teeth due to dental neglect as a child. However, through impeccable oral hygiene since late adolescence, she had managed to stay caries-free for decades, and to maintain a healthy periodontium. She expected to keep her own teeth for life and was willing to invest time, money and efforts to achieve the psychological benefits of a pleasant smile. Her problem was the constant subconscious feelings about her incisor irregularities and uneven gingival margins upon smiling. She had no problems with the deep bite as such and knew that the somatic health benefits of orthodontic correction would be minimal. She had the restorations redone some time after the posttreatment records had been made, at which time she also had a crown placed on the maxillary left lateral incisor. In cases of her type, a comprehensive approach is mandatory for a successful treatment.

\section{Adjunctive Orthodontic Treatment}

Orthodontics is frequently needed as an adjunct to periodontal and restorative treatment to facilitate optimal rehabilitation of mutilated dentitions and appropriate restoration of teeth lost or damaged due to traumatic injuries.

Orthodontics as Adjuncts to Periodontal Treatment. Teeth with severely reduced alveolar support due to advanced plaque-associated loss of the marginal periodontium may no longer sustain the functional occlusal forces. Similarly, the pressure exerted by the surrounding soft tissues during periods of acute inflammation may overcome the resistance offered by the depleted periodontal ligament. Since the center of resistance of the teeth moves apically with the progression of the attachment loss, the tipping moments produced by the forces from occlusion and the inflamed tissues will increase [52]. This explains the frequent clinical observation that tipping and extrusion are common characteristics of pathological tooth migrations $[53,54]$. Severe cases need redirection of the occlusal forces through realignment of the pathologically migrated teeth to facilitate restoration of a stable, functioning occlusion [55]. Provided the patients have been through initial periodontal therapy and are kept free of clinical signs of inflammation, such orthodontic tooth movements can be performed without clinically significant risks of additional attachment loss [54]. However, successful results require extensive planning and comprehensive treatment with full fixed appliances [54, 55].

Orthodontic tooth movements are not associated with attachment loss provided the periodontal tissues are healthy [56]. Accordingly, since the relationship between the cementoenamel junction and the hard and soft tissue attachment levels can be maintained during different types of tooth movement, selective orthodontic tooth extrusion has been proposed as a means to shallow out infrabony pockets. The rationale is to improve the potential for adequate inflammation control [57-59]. However, it should be stressed that the technique requires additional therapy. Firstly, a comparable amount of the crown must be ground down to avoid occlusal interferences, sometimes implying endodontic intervention. Secondly, 
surgical crown lengthening must be performed in the areas with more normal attachment levels to maintain normal crestal bone morphology. Finally, crown therapy may be necessary to restore esthetics. The rationale for such a therapy may therefore be challenged since teeth with advanced attachment loss may be maintained in the long term utilizing conventional treatment approaches [60]. If applied, however, a comprehensive approach is mandatory [58, 59].

Orthodontics as Adjuncts to Restorative Treatment. Teeth adjacent to open extraction sites tend to tip and migrate into the edentulous areas over time [55, 60, 61]. Although inclined tooth positions do not represent a challenge to periodontal health [61], some patients may want to restore the edentulous area for increased functional comfort. If so, the tipped abutments need orthodontic uprighting to facilitate optimal restorative results. Such uprighting is a relatively simple procedure, and can be performed without attachment loss provided the patient exercises appropriate oral hygiene measures. A limited approach may be successful if the problem is limited to the mesially inclined molar. However, whenever additional alignment is necessary for optimal esthetics (fig. 6), a comprehensive approach with full fixed appliances is mandatory.

Another main indication is orthodontic extrusion of fractured teeth to produce the necessary shoulder for successful crown restoration [62]. In such cases, the adaptive apposition of crestal bone to maintain the distance to the cementoenamel junction is undesirable. To prevent that, gingival fiberotomy should be performed at least biweekly during the course of extrusion $[63,64]$. By elimination of the pull exerted by the stretched crestal fibers, the fractured tooth can be moved out of the bony periodontium, affecting neither the bone height nor the level of the gingival margin [63, 64]. A successful result requires careful planning and a comprehensive approach.

\section{Conclusions}

Few malocclusions represent a challenge to dental, periodontal or TM health. Similarly, they rarely cause functional problems. The major reasons for recommending orthodontic corrections of occlusal deviations are therefore psychosocial in nature. However, that does not make orthodontics less important. On the contrary, most patients report that the improved esthetics and functional comfort following the orthodontic corrections represented a significant contribution to their quality of
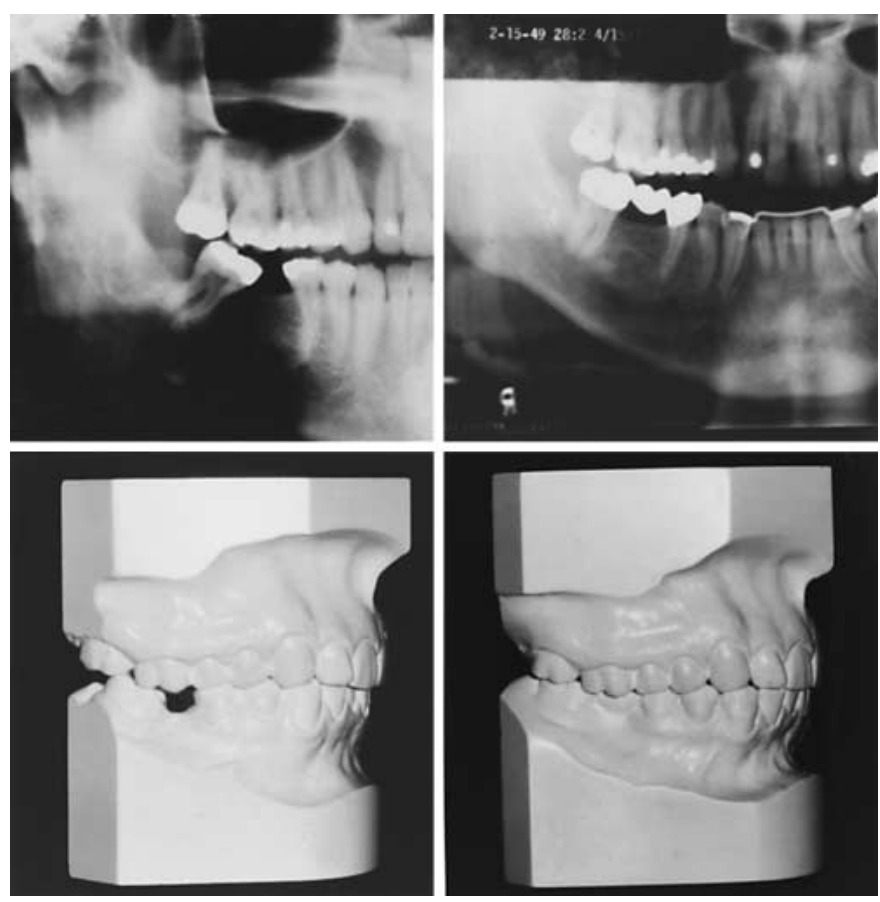

Fig. 6. Pre- and posttreatment records of patient presenting with mesially tipped mandibular right second molar following loss of the first molar. Note favorable axial inclination after treatment, favoring optimal bridge restoration. Also note improved incisor alignment after treatment.

life. With few exceptions, however, optimal results require a comprehensive treatment approach.

As opposed to malocclusions, most dental diseases are self-inflicted. By the intense focus on the significance of prophylactic measures by the dental profession, informed groups of society are expecting to keep their own teeth throughout life by exercising appropriate oral hygiene measures and complying with regular check-ups. This may explain the increased willingness to invest in the comfort and well-being that orthodontic treatment implies, as evidenced by the fact that escalating numbers of the adult population seek orthodontic treatment. Technological advances have made orthodontic treatment simpler and safer over the years. The risk of severe iatrogenic effects is minimal. Due to improved diagnostic abilities, better retention procedures and research on long-term outcomes of different treatment strategies, the chances of achieving long-lasting results have increased. In the case of a clearly defined subjective need, comprehensive orthodontic treatment of minor occlusal deviations may therefore also be justified. 


\section{References}

1 Angle EH: Treatment of Malocclusion of the Teeth and Fractures of the Maxillae: Angle's System, ed 6. Philadelphia, SS White Dental MfG Co, 1900.

2 Kelly JE, Sanchez M, Van Kirk LE: An assessment of the occlusion of teeth of children. Washington, National Center for Health Statistics, 1973, DHEW Publications No (HRA) 74 1612 .

3 Kelly JE, Harvey C: An assessment of the teeth of youths 12-17 years. Washington, National Center for Health Statistics, 1977, DHEW Publication No (HRA) 77-1644.

4 Medin L, Bergström K, Filipsson R, Hannerz H, Jensen R: Need for orthodontic treatment: A suggestion to modify the Indication Index according to Anders Lundström. Kieferorthop Mitt 1995;9:167-183.

5 O'Mullane DM: Some factors predisposing to injuries of permanent incisors in school children. Br Dent J 1973;134:328-332.

6 Järvinen S: Incisal overjet and traumatic injuries to upper permanent incisors. Acta Odontol Scand 1978;36:359-362.

7 Dearing SG: Overbite, overjet, lip-drape and incisor tooth fracture in children. NZ Dent J 1984;80:50-52.

8 Keeling SD, Wheeler TT, King GJ, Garvan CW, Cohen DA, Cabassa S, McGorray SP, Taylor MD: Anteroposterior skeletal and dental changes after early class II treatment with bionators and headgear. Am J Orthod Dentofac Orthop 1998;113:40-50.

9 Tulloch JFC, Phillips C, Proffit WR: Benefit of early class II treatment: Progress report of a two-phase randomized clinical trial. Am J Orthod Dentofac Orthop 1988;113:62-72.

10 Bondevik O: Treatment needs following activator-headgear therapy. Angle Orthod 1995;65: 417-422.

11 Jacobson L, Linder-Aronson S: Crowding and gingivitis: A comparison between mouthbreathers and nosebreathers. Scand J Dent Res 1972;80:500-504.

12 Behlfelt K, Ericsson L, Jacobson L, LinderAronson S: The occurrence of plaque and gingivitis and its relationship to tooth alignment within the dental arches. J Clin Periodontol 1981;8:329-337.

13 Griffiths GS, Addy M: Effects of malalignment of teeth in the anterior segments on plaque accumulation. J Clin Periodontol 1981;8:481490.

14 Ainamo J: Relationship between malalignment of the teeth and periodontal disease. Scand $\mathrm{J}$ Dent Res 1972;80:104-110.

15 Lindhe J, Svanberg G: Influence of trauma from occlusion on progression of experimental periodontitis in the beagle dog. J Clin Periodontol 1974;1:3-4.

16 Helm S, Petersen PE: Causal relation between malocclusion and caries. Acta Odontol Scand 1989;47:217-221.

17 Sadowsky C, BeGole EA: Long-term effects of orthodontic treatment on periodontal health. Am J Orthod 1981;80:156-172.
18 Polson AM: Long-term effect of orthodontic treatment on the periodontium; in McNamara JA, Ribens KA (eds): Malocclusion and the Periodontium. Ann Arbor, University of Michigan Press, 1987, pp 89-100.

19 Polson AM: The relative importance of plaque and occlusion in periodontal disease. $\mathrm{J}$ Clin Periodontol 1986;13:923-927.

20 Geiger AM, Wasserman BH, Turgeon LR: Relationship of occlusion and periodontal disease. VI. Relation of anterior overjet and overbite to periodontal destruction and gingival inflammation. J Periodontol 1973;44:150157.

21 Berg R: Stability of deep overbite correction. Eur J Orthod 1983;5:75-83.

22 Kim T-W, Little RM: Postretention assessment of deep overbite correction in class II division 2 malocclusion. Angle Orthod 1999;69:175-186.

23 Riedman T, Georg T, Berg R: Adult patient's view of orthodontic treatment outcome compared to professional assessment. J Orofac Orthop 1999;60:308-320.

24 Kerosuo H, Kerosuo E, Niemi M, Simola H: The need for treatment and satisfaction with dental appearance among young Finnish adults with and without a history of orthodontic treatment. J Orofac Orthop 2000;61:330-334.

25 Yeh MS-T, Koochek A-R, Vlaskalic V, Boyd R, Richmond S: The relationship of 2 professional occlusal indexes with patients' perceptions of aesthetics, function, speech, and orthodontic treatment need. Am J Orthod Dentofac Orthop 2000; 118:421-428

26 Joondeph DR, Riedel RA: Second premolar serial extraction. Am J Orthod 1976;69:169184.

27 Little RM, Riedel RA, Engst ED: Serial extraction of first premolars - Postretention evaluation of stability and relapse. Angle Orthod 1990;60:225-262.

28 Surbeck BT, Årtun J, Hawkins NR, Leroux B: Association between initial, posttreatment and postretention alignment of maxillary anterior teeth. Am J Orthod Dentofac Orthop 1998; 113:186-195.

29 Ostler S, Kiyak H: Treatment expectations vs outcome in orthognathic surgery patients. Int $\mathbf{J}$ Adult Orthod Orthognath Surg 1991;6:247256.

30 Laine T: Malocclusion traits and articulatory components of speech. Eur J Orthod 1992;14: 302-309.

31 Hayder B, Karabulut G, Özkan S, Aksoy AÜ, Ciger S: Effects of retainers on the articulation of speech. Am J Orthod Dentofac Orthop 1996; 110:535-540.

32 Laskin DM, Greenfield W, Gale E: The President's Conference on the Examination, Diagnosis and Management of Temporomandibular Disorders. Chicago, American Dental Association, 1983.

33 Parker MW: A dynamic model of etiology in temporomandibular disorders. J Am Dent Assoc 1990;120:283-290.
34 Helöe B, Heiberg AN: A follow-up study of a group of female patients with myofacial paindysfunction syndrome. Acta Odontol Scand 1980;38:129-134.

35 McNeill C, Mohl ND, Rugh JD, Tanaka TT: Temporomandibular disorders: Diagnosis, management, education and research. J Am Dent Assoc 1990;120:253-263.

36 Southwell J, Deany IJ, Geissler P: Personality and anxiety in temporomandibular joint syndrome patients. J Oral Rehabil 1990;17:239_ 243.

37 Solberg WK, Bibb CA, Nordström BB, Hansson TL: Malocclusion associated with temporomandibular joint changes in young adults at autopsy. Am J Orthod 1986;89:326-330.

38 Mohlin B, Kopp S: A clinical study on the relationship between malocclusions, occlusal interferences and mandibular pain and dysfunction. Swed Dent J 1978;2:105-112.

39 Egermark-Eriksson I, Ingervall B, Carlsson GE: The dependence of mandibular dysfunction in children on functional and morphologic malocclusion. Am J Orthod 1983;83:187-194.

40 Mohlin B, Thilander B: The importance of the relationship between malocclusion and mandibular dysfunction and some clinical applications in adults. Eur J Orthod 1984;6:192-204.

41 Bush FM: Malocclusion, masticatory muscle, and temporomandibular joint tenderness. J Dent Res 1985;64:129-133.

42 Helm S, Petersen PE: Mandibular dysfunction in adulthood in relation to morphologic malocclusion at adolescence. Acta Odontol Scand 1989;47:307-314.

43 Dworkin SF, Huggins KH, LeResche L, Von Korff M, Howard J, Truelove E, Sommers E: Epidemiology of signs and symptoms in temporomandibular disorders: Clinical signs in cases and controls. J Am Dent Assoc 1990;120: 273-281.

44 Okeson JP, Dickson JL, Kemper JT: The influence of assisted mandibular movement on the incidence of non-working tooth contact. J Prosthet Dent 1982;48:174-177.

45 Dao TT, Lavigne GJ, Charbonneau A, Feine JS, Lund JP: The efficacy of oral splints in the treatment of myofacial pain of the jaw muscles: A controlled clinical trial. Pain 1994;56:8594.

46 Kurol J, Bergland L: Longitudinal study and cost-benefit analysis of the effect of early treatment of posterior cross-bites in the primary dentition. Eur J Orthod 1992;14:173-179.

47 O’Byrn B, Sadowsky C, Schneider B, BeGole E: An evaluation of mandibular asymmetry in adults with unilateral posterior crossbite. Am J Orthod Dentofac Orthop 1995;107:394-400.

48 Hesse KL, Årtun J, Joondeph DR, Kennedy DB: Changes in condylar position and occlusion associated with maxillary expansion for correction of functional unilateral posterior crossbite. Am J Orthod Dentofac Orthop 1997; 111:401-418. 
49 Takada K, Petdachai S, Sakuda M: Changes in dentofacial morphology in skeletal class III children treated by a modified maxillary protraction headgear and chincup: A longitudinal cephalometric appraisal. Eur J Orthod 1993; 15:211-221.

50 McNamara JA: An orthopedic approach to the treatment of class III malocclusion in young patients. J Clin Orthod 1987;21:598-608.

51 Chong Y-W, Ive J, Årtun J: Changes following the use of protraction headgear for early correction of class III malocclusion. Angle Orthod 1996;66:351-362

52 Kusy RP, Tulloch JFC: Analysis of momentforce ratios in the mechanics of tooth movement. Am J Orthod Dentofac Orthop 1986;90: 127-131.

53 Eliasson L-Å, Hugoson A, Kurol J, Siwe H: The effects of orthodontic treatment on periodontal tissues in patients with reduced periodontal support. Eur J Orthod 1982;4:1-9.
54 Årtun J, Urbye KS: The effect of orthodontic treatment on periodontal bone support in patients with advanced loss of marginal periodontium. Am J Orthod Dentofac Orthop 1988;93: 143-148.

55 Melsen B: Management of severely compromised orthodontic patients; in Nada R (ed): Biomechanics in Clinical Orthodontics. Philadelphia, Saunders, 1997, pp 294-319.

56 Ericsson I, Thilander B, Lindhe J: Periodontal conditions after orthodontic tooth movements in the dog. Angle Orthod 1978;48:210-218.

57 Ingber J: Forced eruption. I. A method of treating isolated one and two wall infrabony osseous defects - Rationale and case report. J Periodontol 1974;45:199-206.

58 van Venroy JR, Yukna RA: Orthodontic extrusion of single-rooted teeth affected with advanced periodontal disease. Am J Orthod 1985;87:67-73.

59 Tulloch JFC: Adjunctive treatment for adults; in Proffit WR (ed): Contemporary Orthodontics. St Louis, Mosby Year Book, 1993, pp 554584
60 Lindhe J, Nyman S: The effect of plaque control and surgical pocket elimination on the establishment and maintenance of periodontal health. A longitudinal study of periodontal therapy in cases of advanced disease. J Clin Periodontol 1975;2:67-79.

61 Lundgren D, Kurol J, Thorstensson B, Hugoson A: Periodontal conditions around tipped and upright molars in adults: An intra-individual retrospective study. Eur J Orthod 1992;14: 449-455.

62 Årtun J, Aamdal HM: Severe root resorption of fractured maxillary lateral incisor following endodontic treatment and orthodontic extrusion. Endod Dent Traumatol 1987;3:263-267.

63 Kozlovsky A, Tal H, Lieberman M: Forced eruption combined with gingival fiberotomy: A technique for clinical crown lengthening. J Clin Periodontol 1988;15:534-538.

64 Berglundh T, Marinello CP, Lindhe J, Thilander B, Liljenberg B: Periodontal tissue reactions to orthodontic extrusion: An experimental study in the dog. J Clin Periodontol 1991; 18:330-336. 